Int. J. Electrochem. Sci., 11 (2016) $10874-10883$

International Journal of

ELECTROCHEMICAL

SCIENCE

www.electrochemsci.org

\title{
Voltammetric Sensor Based on 1-Benzyl-4-ferrocenyl-1H- $[1,2,3]$-triazole /Carbon Nanotube Modified Glassy Carbon Electrode; Detection of Hydrochlorothiazide in the Presence of Propranolol
}

\author{
Sakineh Esfandiari Baghbamidi ${ }^{1}$, Hadi Beitollahi ${ }^{2,}$, Somayeh Tajik ${ }^{3}$, Rahman Hosseinzadeh $^{4}$ \\ ${ }^{1}$ Islamic Azad University, Bandar Abbas Branch, Bandar Abbas, Iran \\ ${ }^{2}$ Environment Department, Institute of Science and High Technology and Environmental Sciences, \\ Graduate University of Advanced Technology, Kerman, Iran \\ ${ }^{3}$ Department of Chemistry, Shahid Bahonar University of Kerman, Kerman, Iran \\ ${ }^{4}$ Department of Organic Chemistry, Faculty of Chemistry, University of Mazandaran, Babolsar, Iran \\ *E-mail: h.beitollahi@yahoo.com
}

doi: $10.20964 / 2016.12 .92$

Received: 28 August 2015 / Accepted: 27 October 2016 / Published: 10 November 2016

In this work, 1-benzyl-4-ferrocenyl-1H-[1,2,3]-triazole (BFT) and carbon nanotubes has been applied to construct a modified glassy carbon electrode. This modified electrode showed electrocatalytic activity for oxidation of hydrochlorothiazide (HCT) and reduced the overpotential for oxidation of hydrochlorothiazide about $870 \mathrm{mV}$. Also, the modified electrode can resolve the overlapped voltammetric peaks of hydrochlorothiazide and propranolo into two voltammetric peaks. This property allows to selective determination of hydrochlorothiazide in the presence of propranolol. The transfer coefficient $(\alpha)$ and diffusion coefficient of hydrochlorotjiazide were also investigated. In phosphate buffer solution (PBS) of $\mathrm{pH}$ 8.0, the oxidation currents for hydrochlorothiazide increased linearly from 0.1 to $500.0 \mu \mathrm{M}$ using square wave voltammetry (SWV). The detection limit $(3 \sigma)$ was obtained 0.08 $\mu \mathrm{M}$. The proposed method was successfully applied to the determination of hydrochlorothiazide and propranolol in pharmaceutical and biological samples.

Keywords: Hydrochlorothiazide, Propranolol, Carbon Nanotubes, Chemically modified electrodes

\section{FULL TEXT}

(C) 2016 The Authors. Published by ESG (www.electrochemsci.org). This article is an open access article distributed under the terms and conditions of the Creative Commons Attribution license (http://creativecommons.org/licenses/by/4.0/). 